\title{
Optimum Temperature for HIP Bonding Invar Alloy and Stainless Steel
}

\author{
Takashi Wakui ${ }^{1, *}$, Hideaki Ishii ${ }^{2}$, Takashi Naoe ${ }^{1}$, Hiroyuki Kogawa ${ }^{1}$, Katsuhiro Haga ${ }^{1}$, Eiichi Wakai ${ }^{1}$, \\ Hiroshi Takada ${ }^{1}$ and Masatoshi Futakawa ${ }^{1}$
}

${ }^{1}$ J-PARC Center Japan Atomic Research Agency, Naka-gun, Ibaraki 319-1195, Japan

${ }^{2}$ Metal Technology Co. Ltd., Sanbu-gun, Chiba 289-1751, Japan

\begin{abstract}
The structure of the target vessel for the spallation neutron source will be modified. The Invar alloy which has a low coefficient of thermal expansion has to be reinforced by enclosing it completely in stainless steel using hot isostatic pressing bonding to reduce the thermal deformation of the additional flange. We examined the optimum temperature conditions for HIP bonding the Invar alloy and 316L stainless steel. The metallographic observation and mechanical tests on specimens bonded at $700^{\circ} \mathrm{C}, 900^{\circ} \mathrm{C}, 1100^{\circ} \mathrm{C}$ and $1200^{\circ} \mathrm{C}$ were conducted. The experimental results showed that the bonding region increased when the bonding temperature increased, but the tensile strength reduced when the bonding temperatures increased. The tensile strength of a specimen bonded at $1200^{\circ} \mathrm{C}$ was approximately $10 \%$ lower than that of the Invar bulk. From the residual stress analysis using the ABAQUS code, the tensile stress near the bonding region of the specimen bonded at $700^{\circ} \mathrm{C}$ was found to be $84 \mathrm{MPa}$; this stress increased with the bonding temperature up to $90 \mathrm{MPa}$. From these results, it is concluded that the optimum temperature for bonding temperature was $900^{\circ} \mathrm{C}$. [doi:10.2320/matertrans.M2018346]
\end{abstract}

(Received November 5, 2018; Accepted March 12, 2019; Published April 19, 2019)

Keywords: spallation neutron source, mercury target vessel, Invar alloy, hot isostatic pressing, diffusion bonding, $316 L$ stainless steel

\section{Introduction}

The mercury target vessel employed for the spallation neutron source at the Materials and Life Science Experimental Facility (MLF) in the Japan Proton Accelerator Research Complex (J-PARC) ${ }^{1)}$ was fabricated mainly using 316L austenitic stainless steel (hereinafter 316L SS). The target vessel consists of multi-walled vessels that are approximately $1.3 \mathrm{~m}$ in width, $1.3 \mathrm{~m}$ in height, and $2.5 \mathrm{~m}$ in length. A double-walled shroud with water-cooling channels surrounds the mercury vessel filled with liquid mercury. The pulsed proton beam ( $70 \mathrm{~mm}$ in height and $160 \mathrm{~mm}$ in width) is pulsed repetitively into the liquid mercury through the beam window of the vessel at the rate of $25 \mathrm{~Hz}$; the pulse duration of the beam is $1 \mu \mathrm{s}$. When the proton pulse is injected into the liquid mercury, pressure waves are generated in the mercury by rapid heat deposition and dynamic stress is imposed on the mercury vessel by the propagation of pressure waves. The beam window and the vessels suffer severe damages during operations. These damages include the radiation damage induced by the proton and neutron radiation, ${ }^{2)}$ the cavitation damage caused by the pressure waves in the mercury, and the fatigue damage from the dynamic stresses. ${ }^{3-5)}$ Therefore, at present, the mercury target vessels are replaced annually when operating at $1 \mathrm{MW}$. The used mercury target vessels are temporary located in a storage room where the vessels are loaded into a radiation-shielding container, which is made of stainless steel having a thickness of $100 \mathrm{~mm}$ and located at the J-PARC site. However, the vessels have a large volume; therefore, there is not enough space to store all the vessels throughout the facility service life.

In the radiation distribution after the operation of the target vessel, it is evaluated that the position of high radioactivation is the beam front area of target vessel. To reduce the radiowaste volume, the target vessel has to separate into

*Corresponding author, E-mail: wakui.takashi@jaea.go.jp smaller size to install in the dram can in the hot cell. The methods of separation are usually used by mechanical cutting by cutters and laser beams. But these methods are often contaminated to the wall and floor by radioactive materials. Therefore, we are planned to use the other method by separation structure using HIP bonding technique, which is usually used for the fabrication of vessel structure, for the target vessel handling in the hot cell. The jointing materials are better to use the stress minimum materials between the joints and Invar alloy is thought to be very prominent for it.

The main objective in this study is to investigate the optimum HIP bonding conditions between the Invar alloy and $316 \mathrm{~L}$ SS by focusing on the effect of the bonding temperature. The bonding performance was examined using tensile tests, metallographic observations and hardness tests by parametrically changing the bonding temperature. Furthermore, we conducted residual stress analyses near the bonding region by using the finite element method (FEM).

\section{Design Concept of the Separable Target Vessel Using HIP Bonding Technique}

We investigated the changes to the target structure, which would permit the removal of the high-activity front section of the target. The conceptual design of the separable mercury target vessel is shown in Fig. 1. To reduce the waste volume, the mercury target vessel was divided into a fore part that had a beam window with high specific activity and a rear part that had low activity levels; this would reduce the replacement frequency of the rear part. The two parts were connected by a single flange with multiple piping passages. The separation location was established by considering the waste volume, the thermal load, the clearance with other components and the remote handling requirements for the replacement of the fore part. The size of the flange was $450 \mathrm{~mm} \times 600 \mathrm{~mm}$. The flange needed to be less than $70 \mathrm{~mm}$ in thickness. We used a knife-edge-type seal with a pure-iron gasket to satisfy the required leak tightness of less than $1 \times 10^{-6} \mathrm{~Pa} \cdot \mathrm{m}^{3} / \mathrm{s}$ at 


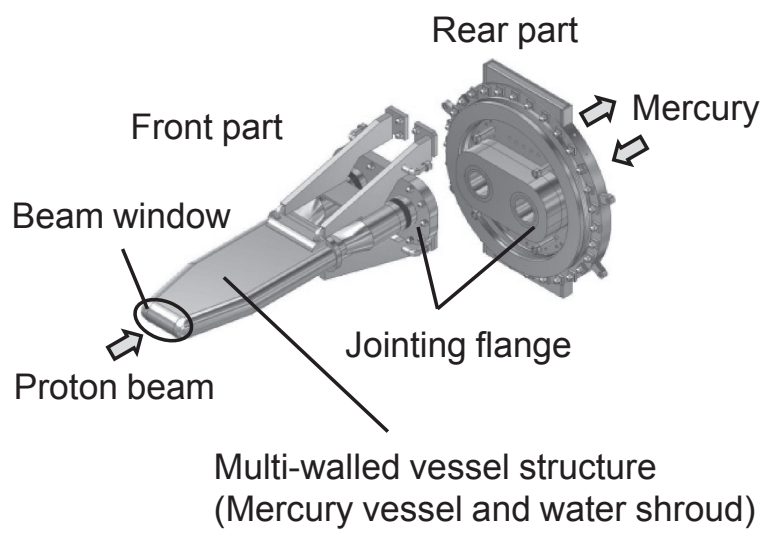

Fig. 1 Jointing flange between the front and rear sections of the proposed mercury target design.

$0.5 \mathrm{MPa}$, which is the design pressure of the mercury vessel. We also considered the cyclic thermal deformation from the beam trips which could affect the seal performance by wedging the knife-edge into a gasket. The maximum wedging depth was $0.3 \mathrm{~mm}$.

The rise in the temperature of mercury because of the proton beam injection depended on the beam profile having the Gaussian distribution. In addition, the flow velocity of the mercury in the central part was less than that in the vicinity of the vessel wall. Therefore, temperature distribution occurred in the mercury in the vessel. For the thermohydraulic analysis with an inlet mercury temperature of $50^{\circ} \mathrm{C}$, the maximum temperature of mercury was approximately $180^{\circ} \mathrm{C}$ at the central part and the temperature distribution at the mercury outlet ranged from $80^{\circ} \mathrm{C}$ to $130^{\circ} \mathrm{C}$. Figure 2 shows the temperature distribution in the flange which is calculated by FEM analysis (Fluent 6.3) in this study. The temperature of the flange depends on that of mercury. When the temperature difference in the flange is $80^{\circ} \mathrm{C}$, the difference of thermal expansion of the flange is approximately $0.1 \mathrm{~mm}$ and one third of the wedging depth. Therefore, the difference of thermal expansion in the flange should be reduced to approximately $0.01 \mathrm{~mm}$ to maintain the seal performance. Although four mixing fins are arranged in a pipe between the vessel and the flange, it is difficult to make the temperature of mercury uniform because of the short pipe. A good method for reducing the thermal deformation that may reduce the seal performance is the use of a low thermal expansion material for the flange. Invar 36 is a nickel-iron alloy containing

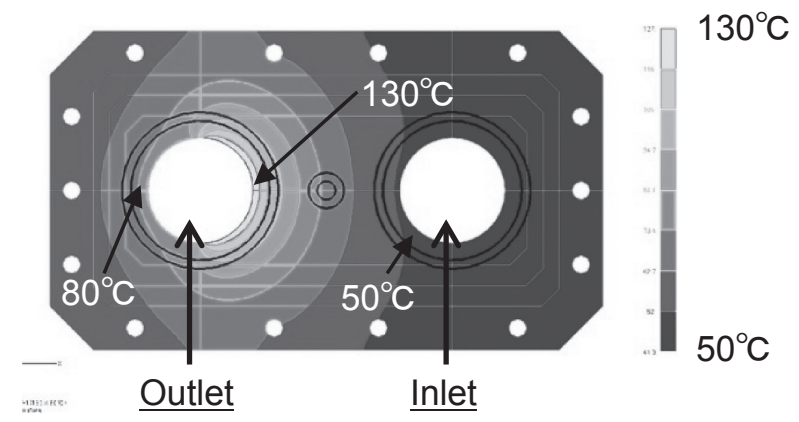

Fig. 2 Calculated temperature distribution on the jointing surface of the flange during 1-MW beam operation in this study. approximately $36 \%$ nickel; it has an austenitic single-phase microstructure and a low coefficient of thermal expansion (CTE) $\left(2 \times 10^{-6} \mathrm{~K}^{-1}\right)$ for the range of temperatures experienced during the operation. The coefficient is onetenth of $316 \mathrm{~L} \mathrm{SS}$, and it is possible for the difference of the thermal expansion of the flange to satisfy the desired value. Recently, Invar alloy is being used as a structural material for cryogenic liquid storage and transport systems. ${ }^{6,7)}$ In general, gas tungsten arc welding is used for jointing by friction stir welding. ${ }^{8)}$ The Invar alloy has a low elastic modulus of approximately $140 \mathrm{GPa} ;{ }^{9)}$ therefore, it should be enclosed within stainless steel to ensure adequate stiffness for the bolting flange. In order to bond whole surface of the Invar block and the stainless steel, hot isostatic pressing (HIP) diffusion bonding which pressurized from all direction was applied. However, the bonding properties between Invar alloy and austenitic stainless steel are not well known. Therefore, to utilize the Invar alloy for the fabrication of the mercury target vessel, we have to examine the HIP bonding conditions carefully. Diffusion-bonded material with these two dissimilar materials will contain residual stress because of the large mismatch in the CTE around the bonding interface. When diffusion-bonded material is used for structural applications, the bonding strength is higher than that of the bulk material, and the residual stress is low around the bonding interface, which reduces the mean stress related to the fatigue strength.

In general, a number of parameters affect the HIP bonding: the surface roughness of the bonding interfaces, the pressure, the bonding temperature, and the time. The surface roughness of the bonding interface and pressure affect the bonded area ratio, which is the ratio of the bonded area to the bond interface. ${ }^{10)}$ The bonding temperature has been shown to affect the thickness of the bonding region rather than the hold time. ${ }^{11)}$

\section{Experimental}

\subsection{Materials}

The chemical compositions of the Invar alloy and 316L SS used in this study are shown in Table 1. Before commencing the experiment, we investigated the changes in the CTE as a function of the temperature before and after heat treatment at $1200^{\circ} \mathrm{C}$ for $2 \mathrm{~h}$ in an atmosphere of argon. Figure 3 shows the relationships between the CTEs of the Invar alloy and the temperature. We observed that the CTE of the Invar alloy did not change significantly after the heat treatment.

\subsection{HIP treatment}

In this study, the hot isostatic pressing equipment (Kobe Steel, Ltd.) was used for the HIP bonding tests. We

Table 1 Chemical compositions of Invar alloy (Fe-36Ni) and 316L SS used in this study. (unit: mass\%)

\begin{tabular}{cccccccccc}
\hline & $\mathrm{C}$ & $\mathrm{Si}$ & $\mathrm{Mn}$ & $\mathrm{P}$ & $\mathrm{S}$ & $\mathrm{Ni}$ & $\mathrm{Cr}$ & $\mathrm{Mo}$ & $\mathrm{Fe}$ \\
\hline Invar alloy & 0.005 & 0.25 & 0.23 & 0.003 & 0.002 & 36.11 & - & - & Bal. \\
\hline 316LSS & 0.08 & 0.58 & 0.83 & 0.026 & 0.001 & 12.11 & 17.62 & 2.08 & Bal. \\
\hline
\end{tabular}




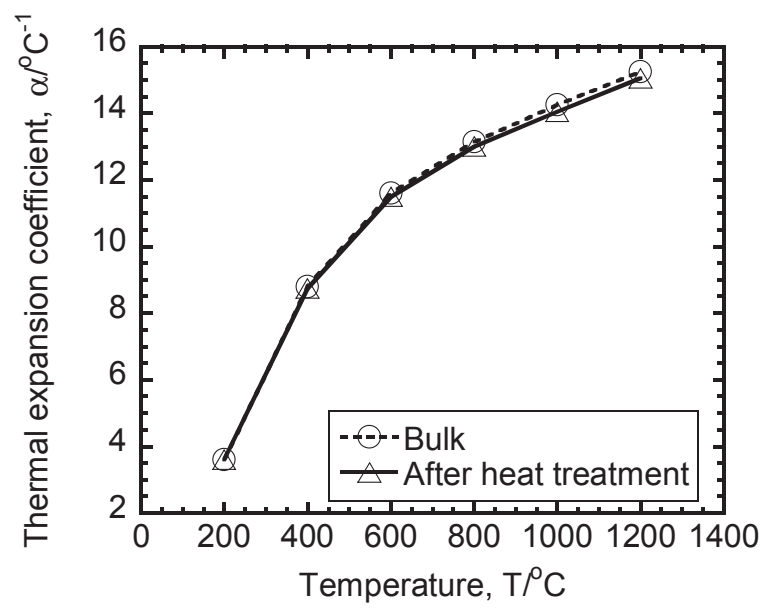

Fig. 3 CTE changes in the Invar alloy with and without the heat treatment as a function of temperature.

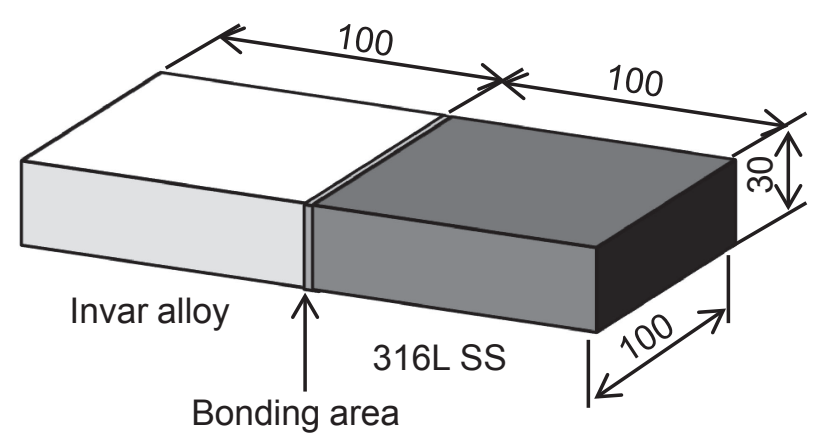

Fig. 4 Two thick plates were placed to conduct the HIP bonding.

conducted HIP bonding without an interlayer by using HIP equipment at four bonding temperatures: $700^{\circ} \mathrm{C}, 900^{\circ} \mathrm{C}$, $1100^{\circ} \mathrm{C}$ and $1200^{\circ} \mathrm{C}$. The heating rate was $300^{\circ} \mathrm{C} / \mathrm{h}$, and the hold time was constant at $2 \mathrm{~h}$; the pressure was $100 \mathrm{MPa}$. The size of the thick plates was $100 \mathrm{~mm} \times 100 \mathrm{~mm} \times 30 \mathrm{~mm}$, and the surface roughness of the finished side surfaces was $\mathrm{Ra}=1.6 \mu \mathrm{m}$. Two thick plates for the HIP bonding were placed as show in Fig. 4. The bonding area generated at the interface.

\subsection{Metallographic observation}

We machined the area near the bonding region from HIP bonded plates and we buff-polished up to $0.06 \mu \mathrm{m}$ for the metallographic observations and hardness tests. To enhance the grain boundary, the Invar alloy side was chemically etched with $15 \%$ Nital. The $316 \mathrm{~L}$ SS side was electrochemically etched in oxalic acid solution. The current value, voltage and etching time were $1 \mathrm{~A} / \mathrm{cm}^{2}, 1.5 \mathrm{~V}$ and $90 \mathrm{~s}$, respectively. The etched specimen was observed under a digital microscope (KEYENCE, VHX-900). The mean grain size of the Invar alloy and $316 \mathrm{~L}$ SS sides were evaluated from the equivalent diameter of the traced grain boundaries. We conducted an energy dispersive X-ray spectrometry (EDX) line analysis using a scanning electron microscopy (SEM) equipped with an EDX system (KEYENCE, VE-7800 and EDAX, Genesis). Our analysis showed that the linelength was $250 \mu \mathrm{m}$, and the elements were $\mathrm{Ni}, \mathrm{Cr}$, and $\mathrm{Fe}$.

\subsection{Hardness tests}

We measured the micro-hardness distribution around the bonding region using a micro-hardness tester (Shimadzu, DUH-W201S). A Bercovich indenter was used to obtain the load and depth curves. The maximum load, the loading rate and the holding time were $29.4 \mathrm{mN}, 0.15 \mathrm{mN} / \mathrm{s}$ and $1 \mathrm{~s}$, respectively. We measured the maximum load Pmax and the depth hmax from the load and depth curves. To calculate the hardness $\mathrm{H}$, we substituted these values into the following equation: ${ }^{12)}$

$$
H=3.86 \times \frac{P_{\max }}{h_{\max }{ }^{2}}
$$

\subsection{Tensile tests}

We machined JIS B plate-type tensile specimens ${ }^{13)}$ from the bonded materials by wire electric discharge machining. The specimen surface was polished with $\mathrm{SiC}$ paper up to a grit size of \#800 in the axial direction. The schematic drawing of the bonded tensile specimen is shown in Fig. 5. The gauge and total length of the tensile specimen with a cross section of $2.5 \mathrm{~mm} \times 12.5 \mathrm{~mm}$ were $60 \mathrm{~mm}$ and $180 \mathrm{~mm}$, respectively.

We conducted quasi-static tensile tests with a constant crosshead speed of $0.0025 \mathrm{~mm} / \mathrm{s}$ and a strain rate of $4.2 \times$ $10^{-5} \mathrm{~s}^{-1}$ in the atmosphere at room temperature by using a hydraulic tensile test machine (Shimadzu, E50kN). The applied load was measured by a load cell and the elongation of the specimen was assumed to be the same as the displacement of the crosshead. Tensile tests were conducted at least three times for each bonding temperature.

\section{Numerical Analyses Method of Residual Stress Distribution}

The residual stress distribution was evaluated around the bonding region of the specimen by numerical analyses using the conventional finite element software ABAQUS ver. 6.14-1. As the first step, a quarter model was applied to the simulation as shown in Fig. 6, and the initial residual stress distribution was checked after the HIP treatment for the plate specimen. The size of the thick plate model is $50 \mathrm{~mm} \times$ $200 \mathrm{~mm} \times 15 \mathrm{~mm}$. The total number of nodes and 8-node hexahedral elements were 517684 and 490050, respectively. The minimum size of the element near the bonding region was $0.25 \mathrm{~mm} \times 0.25 \mathrm{~mm} \times 0.25 \mathrm{~mm}$. We applied an isotropic thermal elastic-plastic model, considering the temperature-dependent material properties (elastic modulus, yield stress, stress-strain curve and coefficient of thermal expansion). ${ }^{14,15)}$ We calculated the residual stress distribution



Fig. 5 JIS B plate-type tensile specimen used in this study (unit is in mm). 


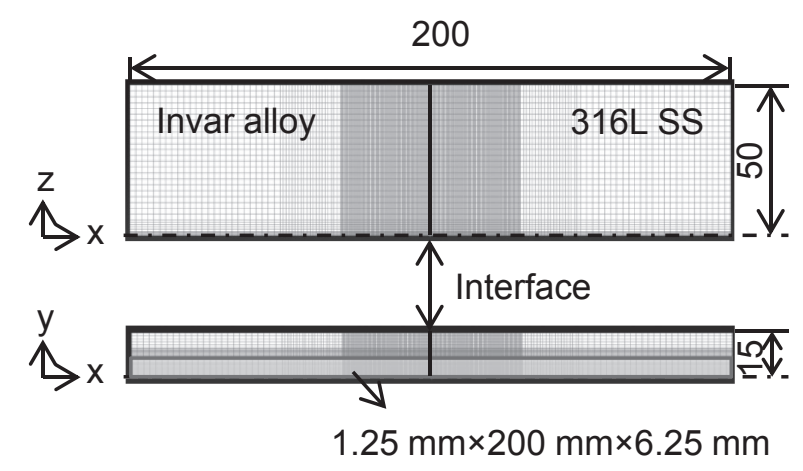

Fig. 6 Analytical model used to evaluate the residual stress distribution near the bonding region. The mesh size is changed in the specimen region.

in the thick plate after reducing the temperature from the bonding temperature to the room temperature. At second step, we deleted elements around specimen parts $(1.25 \mathrm{~mm} \times$ $200 \mathrm{~mm} \times 6.25 \mathrm{~mm}, 51636$ nodes and 41250 elements) and calculated the residual stress distribution in the tensile specimen cut from the HIPed plate was also analyzed.

\section{Results and Discussion}

\subsection{Metallographic observations}

The digital microscope images of the bonding region of each specimen before etching are shown in Fig. 7. Defects, such as cracks, were not observed in the bonding region of any specimen. The bonded interface was obvious in the specimens treated at the bonding temperatures of $700^{\circ} \mathrm{C}$, $900^{\circ} \mathrm{C}$ and $1100^{\circ} \mathrm{C}$; in contrast, the bonded interface was less obvious in the specimens bonded at $1200^{\circ} \mathrm{C}$.

Figure 8 shows the results of the EDX line analysis overlaid on an analyzed SEM image of the specimen surface after etching. In the bonding region, the $\mathrm{Ni}$ concentration decreases from the Invar alloy side to the $316 \mathrm{~L} \mathrm{SS}$ side. By contrast, the $\mathrm{Cr}$ concentration decreases from the $316 \mathrm{~L}$ SS side to the Invar alloy side and almost reaches zero. In Fig. 8, concentration gradient of $\mathrm{Ni}$ and $\mathrm{Cr}$ around the bonding region decreased with increasing bonding temperatures. Figure 9 shows the relationships between the evaluated thickness of the bonding region and the bonding temperature. The thickness of the bonding region estimated from $\mathrm{Ni}$ and $\mathrm{Cr}$ concentrations increased when the bonding temperature was increased. Clearly, when the temperature increases, the thickness also increases at a higher rate.

The relationships among the mean grain sizes (evaluated as an equivalent diameter) and the bonding temperatures are shown in Fig. 10. The mean grain size of both materials became large when the bonding temperatures were increased. The mean grain size of the Invar alloy was larger than that of $316 \mathrm{~L} \mathrm{SS}$. There was little grain growth at the bonding temperature of $700^{\circ} \mathrm{C}$. The mean grain size of $316 \mathrm{~L} \mathrm{SS}$ increased gradually with increasing bonding temperature. For the Invar alloy, the grain size grew with increasing temperature; at $1200^{\circ} \mathrm{C}$, the mean gain size was approximately $0.2 \mathrm{~mm}$. Furthermore, the scatter plot of the mean grain size became large, which suggested the occurrence of secondary recrystallization.

\subsection{Hardness tests}

The hardness distributions around the bonding region for each bonding temperature are shown in Fig. 11. For the specimens bonded at $700^{\circ} \mathrm{C}$, we could not obtain the hardness of the bonding region because of the narrow bonding region (see Fig. 10). The hardness of the bonding region in the specimens bonded at $900^{\circ} \mathrm{C}, 1100^{\circ} \mathrm{C}$ and $1200^{\circ} \mathrm{C}$ increased gradually from the Invar alloy side to the
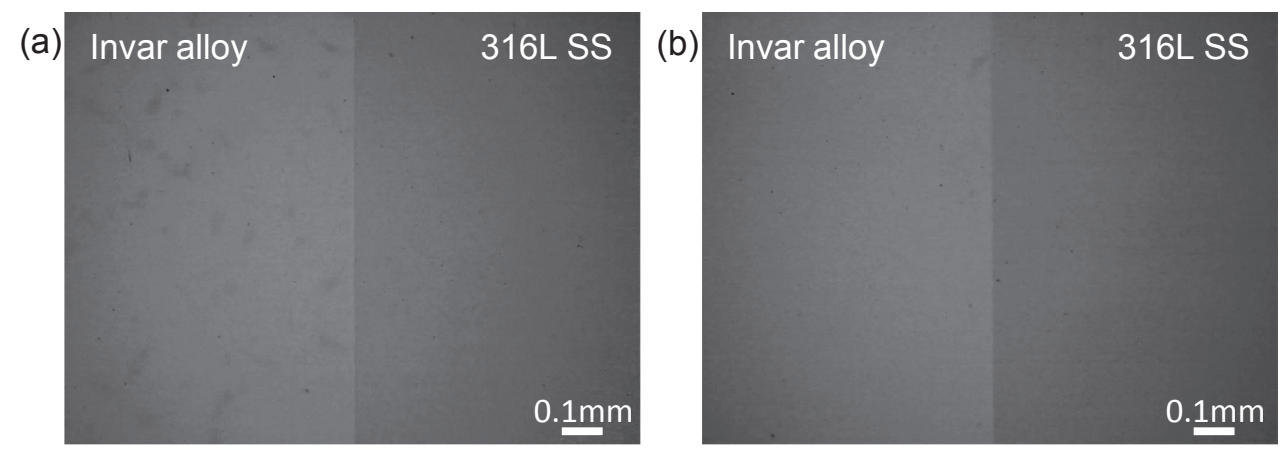

(c)
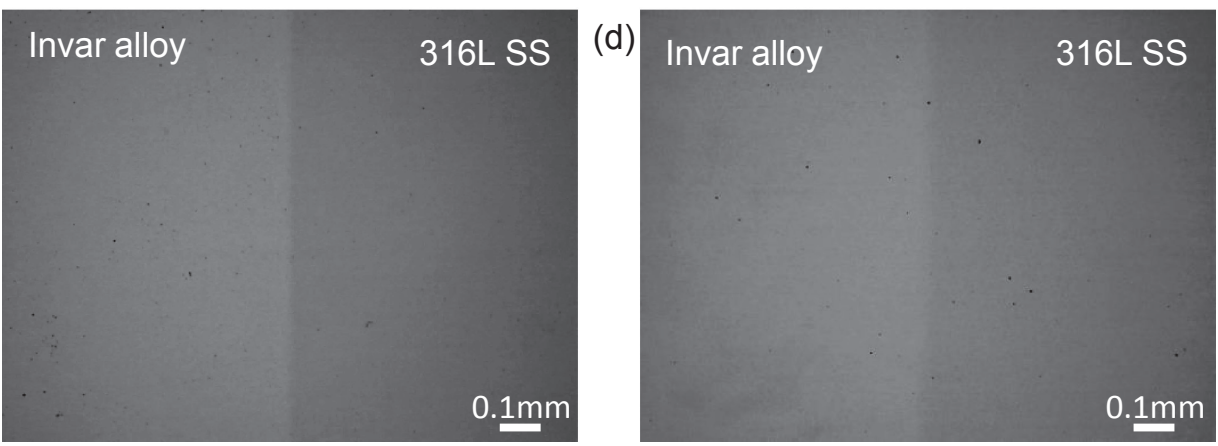

Fig. 7 Digital microscopic images of the surface around the bonding region. 
(a)

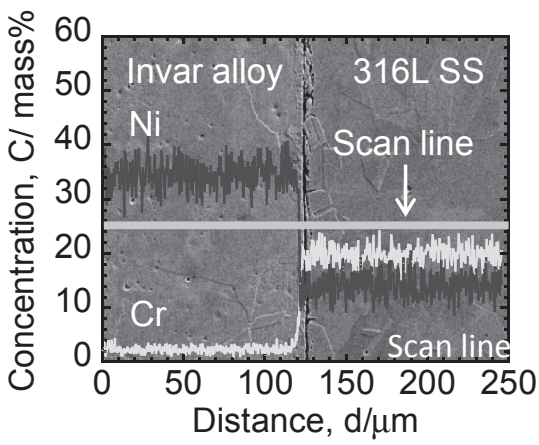

(c)



(b)

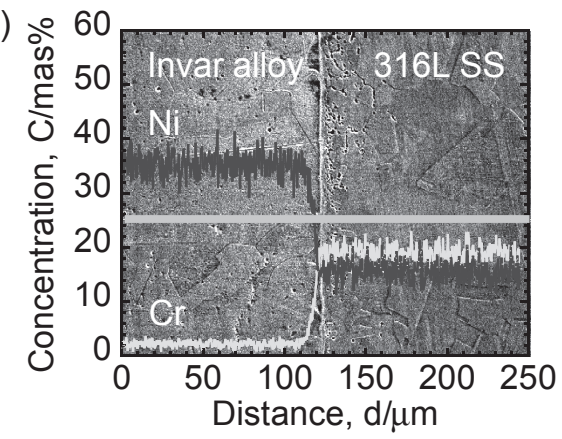

(d)

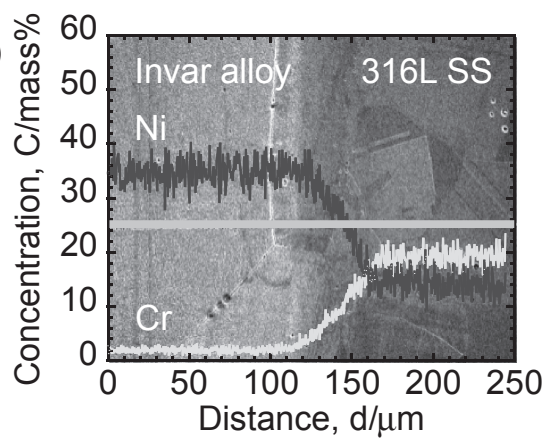

Fig. 8 Results of the EDX line analysis on the surface near the bonding region.

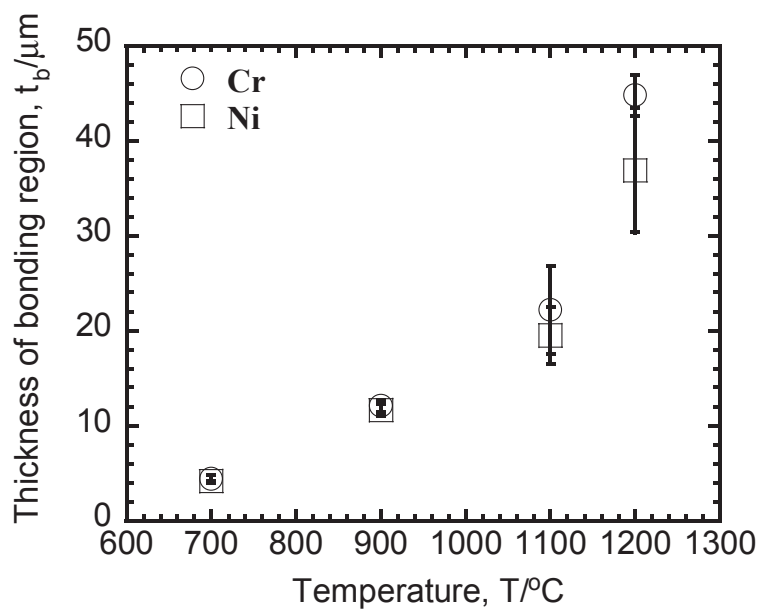

Fig. 9 Relationships between the thickness of the bonding region and bonding temperature.

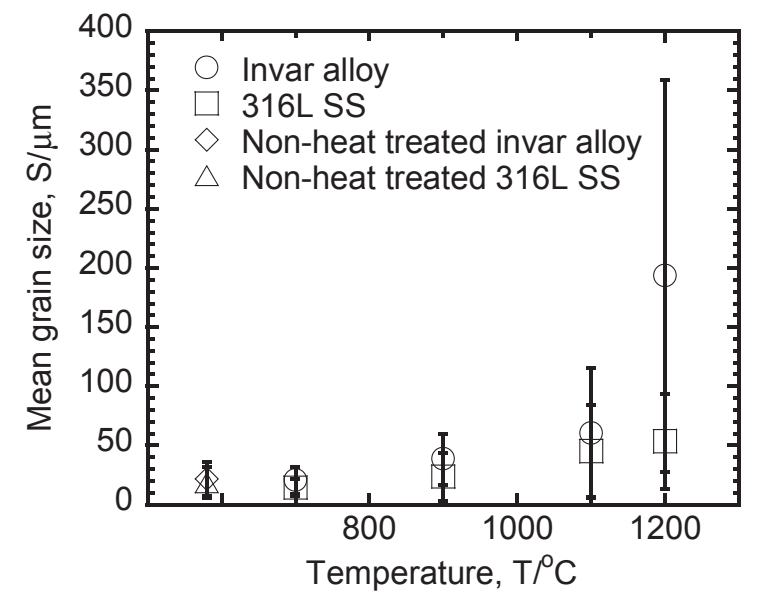

Fig. 10 Relationship between mean grain size and bonding temperature.
316L SS side. The hardness and the slope as a function of the distance from the bonding interface showed a trend similar to the $\mathrm{Cr}$ concentration as shown in Fig. 8.

\subsection{Tensile tests}

As typical examples of the tensile tests, Fig. 12 shows the stress and displacement curves for the specimens bonded at $700^{\circ} \mathrm{C}$ along with the photographs of the fractured specimen. Four specimens fractured at the Invar alloy side, and two specimens fractured at the bonding interface. Gray and black curves in the figure specify that the fracture occurred on the Invar alloy side and the bonding interface, respectively. From Fig. 12, it is clear that before the fracture at the bonding interface, the stress and elongation curves overlapped. The specimen that fractured at the bonding interface did not neck, whereas the failure on the Invar alloy side had obvious necking. The SEM images of the fracture surface of the tensile specimen that fractured at the bonding region are shown in Fig. 13. We observed line-shaped non-bonded areas. This aspect reflected the surface condition before bonding. The ratio of the bonded area to the fractured surface was approximately $75 \%$. All the specimens that bonded at temperatures higher than $700^{\circ} \mathrm{C}$ were fractured at the Invar alloy side. The bonding area increased by microscopic plastic and creep deformations. The temperature of $700^{\circ} \mathrm{C}$ could not annihilate non-bonded areas perfectly.

The tensile strength $\sigma_{B}$ and the true fracture strain $\varepsilon_{f}$ are shown in Fig. 14. The true fracture strain was calculated by the following equation.

$$
\varepsilon_{f}=\ln \left(A_{0} / A_{1}\right),
$$

where $A_{0}$ and $A_{1}$ are the cross section of tensile specimen before and after tensile test. It can be seen that the $\varepsilon_{f}$ of the specimen fractured at the bonded interface is obviously lower 
(a)



(c)



(b)

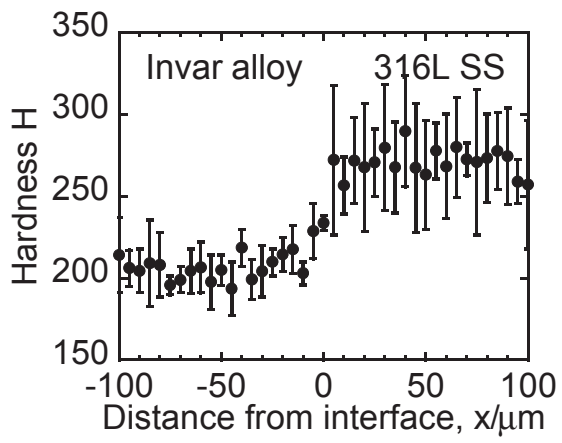

(d)

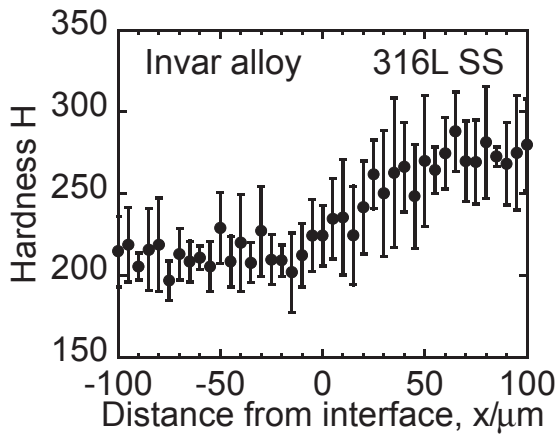

Fig. 11 Distribution of hardness near the boding region of specimens bonded at $700^{\circ} \mathrm{C}, 900^{\circ} \mathrm{C}, 1100^{\circ} \mathrm{C}$ and $1200^{\circ} \mathrm{C}$.

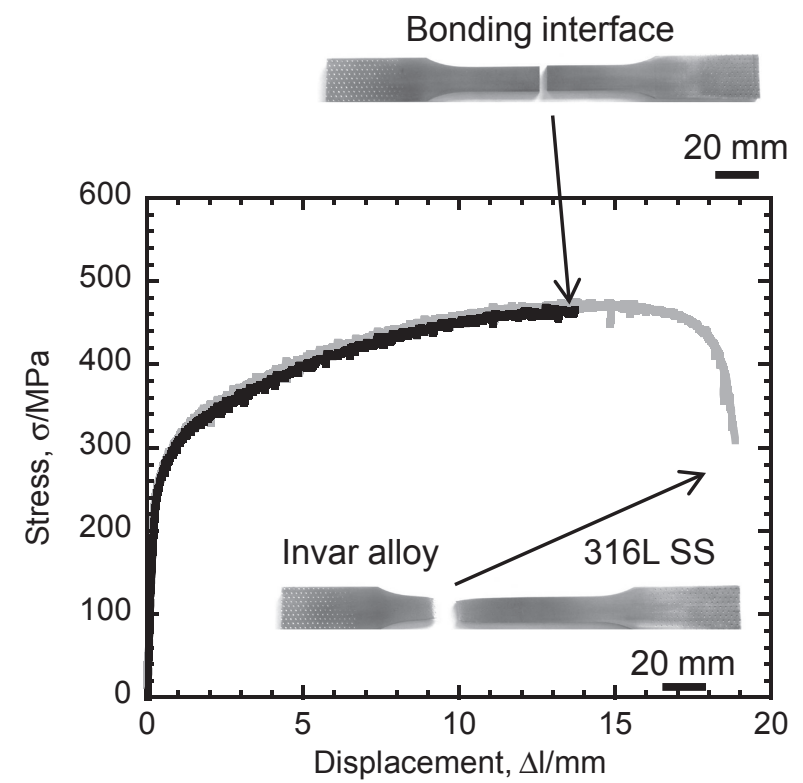

Fig. 12 Typical stress and elongation curves for the $700^{\circ} \mathrm{C}$ case.

than that of the other case. Both $\sigma_{B}$ and $\varepsilon_{f}$ show the same trend at $900^{\circ} \mathrm{C}$ with the Invar alloy that was not treated with heat. In the cases with bonding temperatures higher than $900^{\circ} \mathrm{C}$, the $\sigma_{B}$ and $\varepsilon_{f}$ decreased when the bonding temperatures increased. For the bonding temperature of $1200^{\circ} \mathrm{C}$, $\sigma_{B}$ and $\varepsilon_{f}$ were reduced by approximately $11 \%$ and $23 \%$, respectively, as compared with the Invar alloy not treated with heat.

As shown in Figs. 10 and 14, the mean grain size of the Invar alloy increased when the bonding temperature increased, whereas the $\sigma_{B}$ decreased when the bonding temperature increased. The relationship between the $\sigma_{B}$ and the bonding temperature is summarized in Fig. 15. The horizontal axis

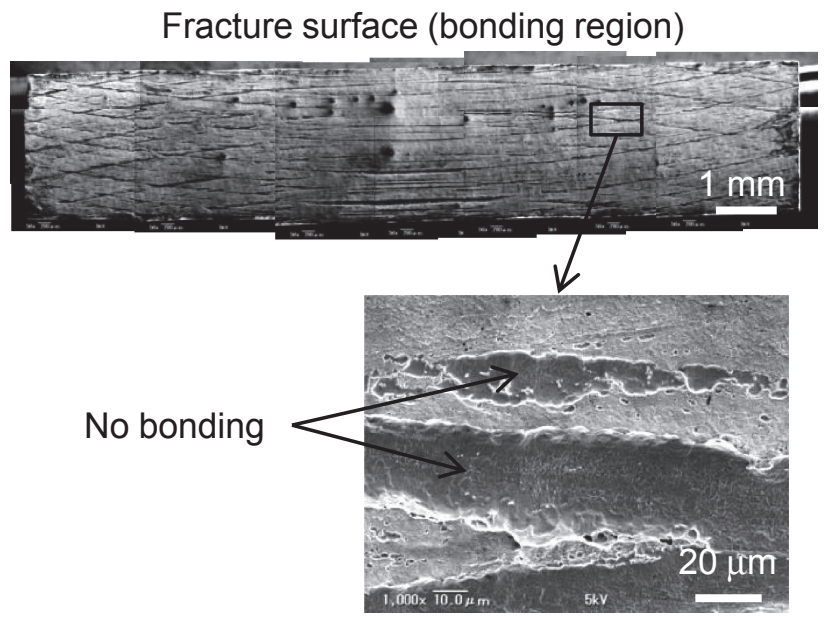

Fig. 13 SEM images of the fracture surface for a specimen that fractured at the bonding interface.

denotes the inverse square root of the mean grain size of Invar alloy, because the failure mostly occurred at Invar alloy side. We found that the mean grain size of the Invar alloy and the tensile strength of the bonded specimen followed the Hall-Petch relationship. ${ }^{16)}$

\subsection{Residual stress distribution}

Figure 16(a) shows the distributions of the residual stress in the longitudinal direction on the surface and in the internal section for a specimen bonded at $1100^{\circ} \mathrm{C}$. On the surface near the bonding interface, we observed a tensile stress on the Invar side and a compressive stress at the $316 \mathrm{~L} \mathrm{SS}$ side. By contrast, an opposite tendency was observed in the internal section. Figure 16(b) shows a high magnification image for the shape around the bonding interface. The deformation scale factor is 10 . We recognized a difference in thickness 




Fig. 14 Change in the tensile strength $\sigma_{B}$ and the true strain $\varepsilon_{f}$ as a function of the bonding temperature. Bonded specimens fractured at the Invar alloy side (circular marks) and the bonding interface (triangular marks).



Fig. 15 Relationship between the tensile strength and mean grain size of the Invar alloy. Temperature labels in the figure denote the bonding temperature.

because the 316L SS shrank more than the Invar alloy. This difference in shrinkage generated a residual stress in the direction of the tensile axis. Figure 17 shows the relationship between the residual stress around the bonding interface and the bonding temperature at each location. The residual stress increased when the bonding temperature was increased.

\section{Optimization of the Obtained Bonding Temperature}

Table 2 summarizes the mechanical properties of the bonded specimens investigated in this study. The thickness of the bonding region increased when the bonding temperature was increased. The $\sigma_{B}$ bonded at $700^{\circ} \mathrm{C}$ and $900^{\circ} \mathrm{C}$ are almost the same as the $\sigma_{B}$ of the Invar alloy bulk not treated with heat. Beyond $900^{\circ} \mathrm{C}$, the $\sigma_{B}$ decreased when the bonding temperature was increased. The specimen bonded at $700^{\circ} \mathrm{C}$ fractured at the bonding interface and the true strain was small. The residual stress increased when the bonding temperature was increased. Based on the results of the (a)

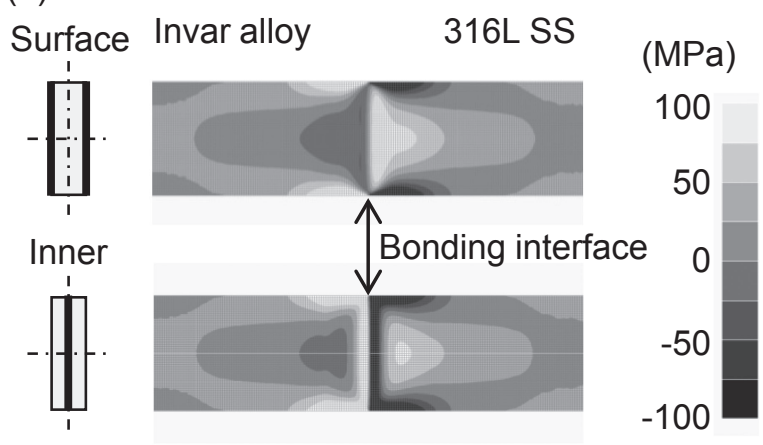

(b)

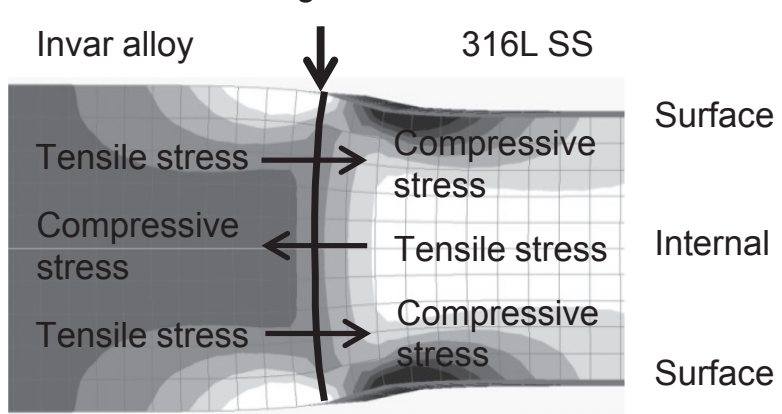

Fig. 16 Results of the numerical analysis of the specimen bonded at $1100^{\circ} \mathrm{C}$. (a) Distribution of residual stress in the tensile axis direction on the surface and the inner portion. (b) Deformation of the bonding region.



Fig. 17 Relationship between the residual stress near the bonding region and the bonding temperature.

Table 2 Mechanical properties of bonded specimens obtained for each bonding.

\begin{tabular}{lcccc}
\hline & $700^{\circ} \mathrm{C}$ & $900^{\circ} \mathrm{C}$ & $1100{ }^{\circ} \mathrm{C}$ & $1200{ }^{\circ} \mathrm{C}$ \\
\hline Thickness of bonding region $(\mu \mathrm{m})$ & 4 & 12 & 21 & 41 \\
\hline Tensile strength $(\mathrm{MPa})$ & 454 & 457 & 433 & 408 \\
\hline True fracture strain & 0.22 & 0.65 & 0.52 & 0.50 \\
\hline Residual stress $(\mathrm{MPa})$ & 59 & 70 & 80 & 81 \\
\hline
\end{tabular}


specimens used in this study, we could conclude that the best bonding temperature was $900^{\circ} \mathrm{C}$, because the specimen bonded at $900^{\circ} \mathrm{C}$ had the same mechanical properties as the Invar alloy that was not treated with heat.

\section{Conclusions}

To maintain the seal performance of the flange in the separable mercury target, we used the Invar alloy with a low CTE as the flange material; this reduced the thermal deformation. We examined the optimization of the bonding temperature of the HIP diffusion bonding between the Invar alloy and the $316 \mathrm{~L} \mathrm{SS}$ as the main structural materials of the vessel. The bonding temperatures that we examined parametrically were $700^{\circ} \mathrm{C}, 900^{\circ} \mathrm{C}, 1100^{\circ} \mathrm{C}$ and $1200^{\circ} \mathrm{C}$. After the HIP bonding, we performed tensile tests at room temperature and residual stress analyses using FEM. We arrived at the following conclusions:

(1) The thickness of the bonding region estimated from the concentrations of $\mathrm{Cr}$ and $\mathrm{Ni}$ increased when the bonding temperatures were increased.

(2) The hardness of the bonding region showed the hardness between the Invar alloy and the $316 \mathrm{~L} \mathrm{SS}$, and the bonding region was not fragile.

(3) The grain size increased when the bonding temperature was increased.

(4) When bonding at $700^{\circ} \mathrm{C}$ fractures occurred at the bonding interface, and the tensile strength and the true fracture strain showed the lowest values as compared with the other bonding temperatures.

(5) The tensile strength of the specimen bonded at $900^{\circ} \mathrm{C}$ was the same as that of the Invar alloy that was not treated with heat.

(6) The tensile strength of the specimen bonded at $1100^{\circ} \mathrm{C}$ and $1200^{\circ} \mathrm{C}$ decreased when the bonding temperature was increased.

(7) The residual stress near the bonding interface increased when the bonding temperature was increased.

(8) Given the temperature conditions used in this study, we concluded that the optimum bonding temperature was $900^{\circ} \mathrm{C}$, because the specimen bonded at $900^{\circ} \mathrm{C}$ had the same mechanical properties as the Invar alloy that was not treated with heat.

\section{REFERENCES}

1) F. Maekawa et al:: J. Nucl. Inst. Meth. Phys. Res. A 620 (2010) 159165.

2) M. Harada, N. Watanabe, C. Konno, S. Meigo, Y. Ikeda and K. Niita: J. Nucl. Mater. 343 (2005) 197-204.

3) M. Futakawa, T. Naoe, C.C. Tsai, H. Kogawa, S. Ishikura, Y. Ikeda, H. Soyama and H. Date: J. Nucl. Mater. 343 (2005) 70-80.

4) T. Wakui, T. Naoe, H. Kogawa and M. Futakawa: Nucl. Instrum. Methods Phys. Res., Sect. A 600 (2009) 150-153.

5) K. Haga, H. Kogawa, T. Wakui, T. Naoe, M. Futakawa, S. Yamazaki and N. Tanaka: Nucl. Instrum. Methods Phys. Res., Sect. A 600 (2009) 64-67.

6) J.J. Wilson: Cryogenics 14 (1974) 115-120.

7) F.S. Harris: Cryogenics 33 (1993) 772-777.

8) M. Teshigawara, M. Harada, M. Ooi, T. Kai, F. Maekawa and M. Futakawa: J. Nucl. Mater. 431 (2012) 212-217.

9) A.V. Deryabin, V.K. Kazantsev and B.N. Shvetsov: J. Magn. Magn. Mater. 51 (1985) 98-102.

10) O. Ohashi and Y. Kaieda: Qu. J. Jpn. Weld. Society 6 (1988) 493.

11) M. Tsukamoto, S. Sakamoto and A. Yamamoto: J. Japan Inst. Met. Mater. 75 (2011) 592-599.

12) Japan Industrial Standard: Z2255 (Method for ultra-low loaded hardness test, 2003) pp. 1-5.

13) Japan Industrial Standard: Z2241 (Metallic materials - Tensile testing Method of test at room temperature, 2011) pp. 31-33.

14) J.M. Nan, G.X. Li and K.W. Xu: J. Mater. Process. Technol. 114 (2001) 36-40.

15) A. Maekawa, M. Noda, T. Omaya and S. Takahashi: INSS JOURNAL 16 (2009) 62-73.

16) N. Hansen: J. Scripta Mater. 51 (2004) 801-806. 